They often seem to have a regression coefficient of the "wrong" sign, but the variable seems counterintuitive only if considered in isolation. Consideration of other variables in the model makes the reason clear. Variables with counterintuitive sign compensate for the excess effects of other variables in the model, so that excluding them removes this opportunity for negative feedback. The result is a model that is both less subtle and less predictive - in short, the downside of transparency.

Another illustration of the tension between statistics and politics is the inclusion of the need variable defined as the percentage of dependants in no carer households. It is only marginally significant $(t=2.17$, table 1$)$ and explains just $0.06 \%$ of the variance-far less than the other variables in the model and probably less than the variables excluded as counterintuitive. So it is irrelevant in terms of improving the fit and increases the complexity of the need model by a third. Yet it is included because it is intuitively appealing.

So the good news for practitioners is that the need model is both simple and plausible. The bad news is that the model fails to explain three eighths of the variation in prescription costs, and this fraction could be reduced if the model were allowed to be less transparent.

Competing interests: None declared.

\title{
Analysis of the ability of the new needs adjustment formula to improve the setting of weighted capitation prescribing budgets in English general practice
}

\author{
Darrin L Baines, David J Parry
}

Editorial by Majeed General practice p 284

Health Economics Facility, Health Services

Management Centre, University of Birmingham, Park House, Birmingham B15 2RT

Darrin L Baines senior lecturer in health economics David J Parry lecturer in health economics

Correspondence to: D L Baines Bainesdl@hsmc. bham.ac.uk

BMJ 2000;320:288-90
In April 1991 prescribing budgets were introduced into English general practice as part of the fundholding and indicative prescribing schemes. ${ }^{1}$ The schemes were designed to control the growth in public expenditure on drugs and to reduce the variation in prescribing costs that existed between general practitioners in different parts of the country. Initially, practice level prescribing budgets were set on a historical cost basis. This approach was criticised, however, for being inequitable and for possibly rewarding high cost, inefficient practices with more funds. ${ }^{2}$ In response, a move to budgets set on a weighted capitation basis was recommended as a means of promoting equity while ensuring that funding levels reflected the needs of patients locally.

The identification of several limitations of the weighted capitation formula that was used to help set prescribing budgets in England from 1993-4 onwards led to a debate about the desirability of using such an approach. Majeed argued that variations in general practice prescribing costs were too large to be explained in this way. ${ }^{3}$ He suggested that the rigid, inflexible application of weighted capitation formulas to help set practice level prescribing budgets should be avoided. In a similar vein, Majeed and Head argued that weighted capitation formulas were very crude tools for determining general practice prescribing budgets and should be used only as a guide to allocations. ${ }^{4}$ Greenhalgh concluded that such formulas should not be used as substitutes for factors such as reflection or negotiation during the budget setting process. ${ }^{5}$ Maxwell, Howie, and Pryde reported that the formula used to help set practice level budgets failed to take account of factors such as patients' values, beliefs, and expectations. ${ }^{6}$ Finally, Smith argued that the formula did not reflect all patient related variations in costs, random variations in need, and differences in clinical practice. In consequence, he argued, such formulas should be used with great caution. ${ }^{7}$

Despite concerns about the use of weighted capitation formulas in the setting of practice level prescribing budgets, the "new NHS" white paper announced that from April 1999 onwards all practices in England

\section{Summary points}

The existing weighted capitation formula used for setting prescribing budgets in English general practice has known limitations

A new needs adjustment formula was designed to address many of these limitations

As the new formula was developed using a similar procedure for identifying patients' needs, it embodies some of the limitations of its predecessor

In particular, the new formula may have institutionalised historical prescribing patterns and may fail to measure patients' needs directly

The new formula should be subjected to piloting and a formal evaluation before it is recommended for use nationally

would be allocated a budget for prescribing under the auspices of the newly established primary care groups. ${ }^{8}$ To help improve the basis on which such budgets are set, the NHS Executive commissioned researchers from York University and the Prescribing Support Unit to identify which factors other than patient age, sex and temporary resident status were associated with variations in costs. In June 1999 the NHS Executive published the final formula produced by the research team with the recommendation that it be used by primary care groups to help guide practice level prescribing allocations. In response, we outline some of the main deficiencies of the formula and conclude that the approach used during its construction may have institutionalised historical prescribing patterns and failed to measure variations in patients' needs for prescribed drugs. 


\section{Development of a weighted capitation formula for prescribing}

As practice level prescribing budgets had not been set before April 1991, the NHS lacked a robust weighted capitation formula for their allocation. At the time, the only available prescribing cost denominator was the "prescribing unit," which weighted patients aged under 65 years as one and those aged 65 and over as three. The prescribing unit was used by many health authorities to help compare costs between practices within their areas. Evidence suggested, however, that the measure failed to account for differences in age and sex related variations in prescribing spending. ${ }^{9}$ In response, the ASTRO-PU (age, sex, and temporary resident originated prescribing unit) was developed; this contained weights believed to reflect the distribution of prescribing costs, in relation to age and sex, in English general practice. ${ }^{10}$ Although the ASTRO-PU was superior to the prescribing unit, the architects of the new measure stated that many factors other than the age and sex structure of a practice population influenced prescribing and that its weightings accounted for only about $25 \%$ of the variations in costs between practices. ${ }^{10}$

Not only was the ASTRO-PU unable to explain $75 \%$ of the variation in prescribing costs per practice nationally, but its explanatory power was also challenged by changes in prescribing patterns over time. As prescribing patterns had changed substantially since the measure's construction during the early 1990s, the ASTRO-PU's weights were recalculated using data from November 1995 to October 1996. The new measure, the ASTRO(97)-PU, gave larger weights to patients under the age of 65 and reduced some of the weightings for older patients. Given the greater accuracy of these weightings, the architects of the ASTRO(97)-PU suggested that these new weightings should be used for budget setting. ${ }^{11}$

Although the ASTRO(97)-PU was designed to be more accurate than the ASTRO-PU, it embodied several weaknesses similar to those of its predecessor. In particular, the new measure used only one set of weightings for all practices nationally and did not measure need in terms of patients "capacity to benefit" from prescribed drugs-that is, their ability to improve their health status through the consumption of pharmaceutical products. ${ }^{12}$ In consequence, the ASTRO(97)-PU was unable to guarantee that $(a)$ practices would be funded for all legitimate variations in costs, (b) its national weights were applicable at a local level, and (c) prescribing allocations would accurately reflect patients' needs.

\section{New needs adjustment formula for prescribing}

In response to the publication of the "new NHS" white paper, the NHS Executive commissioned researchers from the University of York and the Prescribing Support Unit to develop a needs based formula for adjusting prescribing allocations made on the basis of the ASTRO(97)-PU. ${ }^{13}$ The logic behind this move was that such a formula would be able to improve the basis on which budgets are set by accounting for the factors related to need not included in the ASTRO(97)-PU. The researchers used multiple regression modelling to explain practice level variations in prescribing expendi-

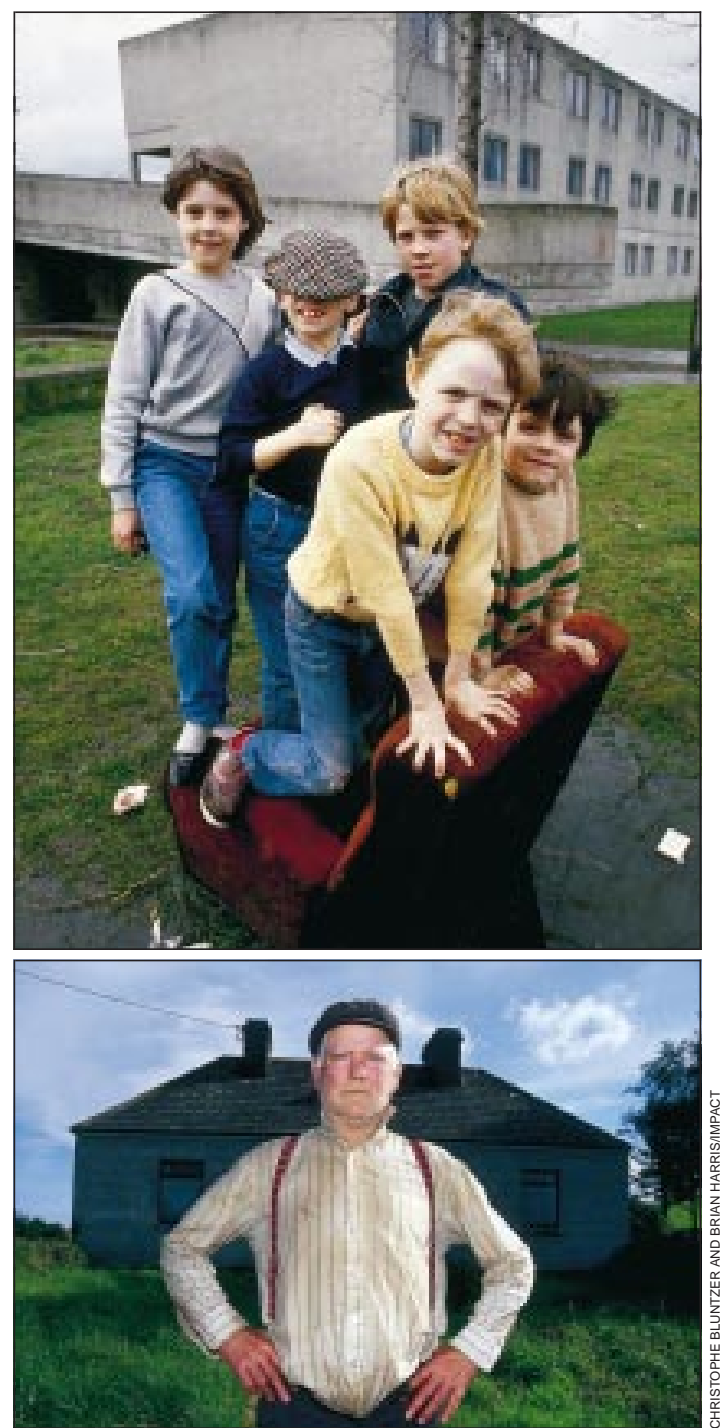

Accurately identifying patients' needs is crucial to developing an appropriate needs adjustment formula

tures. Based on data for 8506 English practices for $1997-8$ their model explained $41 \%$ of the variation in costs, above that accounted for by the ASTRO(97)-PU with four "need" and five "supply" variables (plus a variable designed to correct for differences in list inflation between practices). Although the scheme was abolished in March 1999, the model also included a variable designed to account for the assumed endogeneity of fundholding status among the practices sampled.

The need variables included in the needs adjustment formula were based on responses to questions asked by the 1991 census. In this context, the use of census variables presents two main problems. Firstly, such variables are prone to random and systematic errors and, in some areas, may not accurately reflect the true values of the variables that they are trying to measure. ${ }^{145}$ Secondly, they do not measure need in terms of patients' capacity to benefit from available interventions-for example, the "permanent sickness" variable was designed to measure the proportion of the population unable to work owing to long term illness or disability and was not designed to measure people's ability to benefit from prescribed drugs. Despite these limitations, the Advisory Committee on 
Resource Allocation for the NHS in England recommended a revised version of the needs adjustment formula for use by primary care groups, which only included the variables for permanent sickness, no carer, students, and babies. ${ }^{16}$ The supply variables, on the other hand, were dropped from the recommended formula, as they were not deemed to represent need related variations in costs.

\section{Discussion}

The architects of the ASTRO(97)-PU and of the needs adjustment formula adopted a "positive" approach to explain practice level variations in prescribing coststhat is, they based their research on prescribing patterns that were observed during the years in which they sampled their data. The researchers could have adopted a "normative" approach, whereby they would have specified the factors that should determine variations in costs and the influence they should have during the budget setting process. ${ }^{17}$ A normative statement could be that "extra funding should be provided for patients exempt from the prescription charge" or that " 15 times as much should be spent on men aged over 75 years."

By using a positive approach, the researchers may have fallen foul of the "naturalistic fallacy"-that is, they inappropriately attempted to derive "ought to" from "is"-by recommending that pharmaceutical budgets should be based on previously observed prescribing patterns. ${ }^{18}$ To avoid the fallacy, observed prescribing patterns must be a suitable basis for determining future prescribing spends. Prescribing behaviour in one time period may not reflect changes in pharmaceutical technology and patients' needs in the next (and may embody an unknown amount of inappropriate and inefficient prescribing). ${ }^{19}$ Because a positive approach was used, practice allocations were based on nationally observed, historical prescribing patterns rather than on patients' needs locally.

\section{Common deficiencies}

As a positive approach was used to construct both the ASTRO(97)-PU and the needs adjustment formula, both formulas may share a common set of deficiencies. Firstly, they may be unable to account for all causes of prescribing cost variation (such as differences in individual prescribing behaviour and random fluctuations), particularly as their construction is limited by the availability of high quality and appropriate data. ${ }^{20}$ In consequence, legitimate causes of prescribing cost variations (such as differences in clinical practice, prescription exemption rates, and the number of nursing home patients) may not be funded. ${ }^{21}{ }^{22}$ Secondly, as they recommend only one set of weights for all practices nationally, they may be of little use to primary care groups, which have to set budgets that reflect local variations in need. ${ }^{23}$ Thirdly, as neither formula is able to measure patients' capacity to benefit from prescribed drugs, budgets set on this basis may not reflect local needs. Finally, instead of addressing the problems associated with budget setting on a historical cost basis, the ASTRO(97)-PU and the needs adjustment formula may have institutionalised historical prescribing patterns, with the result that they wrongly attempted to predict future prescribing patterns on the basis of past trends. ${ }^{24}$

\section{Piloting before use}

Given the possible limitations of the new needs adjustment formula for prescribing, the formula should be subjected to piloting in a small number of practices before it is adopted nationally. Such piloting should assess the effect of the formula on practitioners' prescribing behaviour and the volume and types of medicines that patients receive. Also, the assessment should examine the extent to which, at a local level, the national weights attached to the variables included in the formula reflect patients' capacity to benefit from prescribed drugs. Once these data on the implications of its use have been collected, the NHS Executive should consider whether the formula is a suitable basis on which to set practice allocations and should issue instructions to primary care groups accordingly. Piloting may lead to the conclusion that weighted capitation formulas of this type are an inadequate basis on which to set such budgets and that other means of allocating prescribing funds need to be found.

We thank Dr Azeem Majeed and Professor Alain Li Wan Po for comments on an earlier draft of this paper.

Contributors: DLB and DJP were jointly involved in the critical analysis and the writing of this paper. DB is the guarantor. Funding: The authors both work for the Health Economics

Facility. No additional funding was secured for this work.

Competing interests: None declared.

1 Department of Health. Working for patients. London: HMSO, 1989.

2 Day P, Klein R. Variations in budgets of fundholding practices. BMJ 1991;303:168-70.

3 Majeed A. Allocating budgets for fundholding and prescribing. BMJ 1996;313:1274-5.

4 Majeed A, Head S. Capitation based prescribing budgets will not work. BMJ 1998;316:748-53.

5 Greenhalgh T. Effective prescribing at practice level should be identified and rewarded. $B M J$ J 1998;316:750-3.

6 Maxwell M, Howie JGR, Pryde CJ. A comparison of three methods of setting prescribing budgets, using data derived from defined daily dose analyses of historic patterns of use. BrJ Gen Pract 1998;48:1467-2.

7 Smith PC. Setting budgets for general practice in the new NHS. BMJ 1999;318:776-9.

8 Department of Health. The new NHS. London: Stationery Office, 1997. (Cm 3807.)

9 Sleator DJD. Towards accurate prescribing analysis in general practice: accounting for the effects of practice demography. Br J Gen Pract 1993;43:102-6.

10 Roberts SJ, Harris CM. Age, sex, and temporary resident originated prescribing units (ASTRO-PUs): new weightings for analysing prescribing of general practices in England. BMJ 1993;307:485-8

11 Lloyd DCEF, Roberts DJ, Sleator D. Revision of the weights for the age sex temporary resident originated prescribing unit. $\mathrm{Br} J$ Med Econ 1997;11:81-5

12 Culyer AJ. Need and the National Health Service:economics and social choice. London: Martin Robertson, 1976.

13 Rice N, Dixon P, Lloyd D, Roberts, D. Derivation of a needs based capitation formula for allocating prescribing budgets. York: Centre for Health Economics, 1999. (Occasional paper.)

14 Majeed FA, Cook DG, Poloniecki J, Griffiths J, Stones C. Sociodemographic variables for general practices: use of census data. $B M J$ 1995;310:1373-4.

15 Majeed FA, Cook DG, Poloniecki J, Martin D. Using data from the 1991 census. BMJ 1995;310:1511-4.

16 NHS Executive. Report of the Advisory Committee on Resource Allocation 1998. London: Department of Health, 1999.

17 Baines DL, Whynes DK. The use of the ASTRO-PU and the ASTRO(97)-PU in the setting of prescribing budgets in English general practice.J Clin Pharm Ther 1998;23:229-34.

18 Searle JR. How to derive "ought" from "is." Philosophical Review 1964;73:43-58.

19 Audit Commission. A prescription for improvement: towards more rational prescribing in general practice. London: HMSO, 1994.

20 Carr-Hill R, Rice N, Smith PC. Towards locally based resource allocation in the NHS. York: University of York, 1998. (Centre for Health Economics discussion paper.)

21 Whynes DK, Baines DL, Tolley KH. Explaining variations in general practice prescribing costs per ASTRO-PU (age, sex, and temporary resident originated prescribing unit). BMJ 1996;312:488-9.

22 Lloyd D, Scrivener G. Prescribing for patients in homes: a revised ASTRO-PU. Prescriber 1998;5(Apr):33-6.

23 Newdick C. Primary care groups and the right to prescribe. BMJ 1998;317:1361-5.

24 Popper K. The poverty of historicism. Reading: Cox and Wyman, 1957.

(Accepted 22 December 1999) 